\title{
Time Intervals for Maintenance of Offshore Structures Based on Multiobjective Optimization
}

\author{
Dante Tolentino and Sonia E. Ruiz \\ Instituto de Ingeniería, Universidad Nacional Autónoma de México, 04510 Coyoacán, DF, Mexico \\ Correspondence should be addressed to Dante Tolentino; dtolentinol@iingen.unam.mx
}

Received 22 March 2013; Revised 28 June 2013; Accepted 5 July 2013

Academic Editor: Dan Simon

Copyright ( 2013 D. Tolentino and S. E. Ruiz. This is an open access article distributed under the Creative Commons Attribution License, which permits unrestricted use, distribution, and reproduction in any medium, provided the original work is properly cited.

With the aim of establishing adequate time intervals for maintenance of offshore structures, an approach based on multiobjective optimization for making decisions is proposed. The formulation takes into account the degradation of the mechanical properties of the structures and its influence over time on both the structural capacity and the structural demand, given a maximum wave height. The set of time intervals for maintenance corresponds to a balance between three objectives: (a) structural reliability, (b) damage index, and (c) expected cumulative total cost. Structural reliability is expressed in terms of confidence factors as functions of time by means of closed-form mathematical expressions which consider structural deterioration. The multiobjective optimization is solved using an evolutionary genetic algorithm. The approach is applied to an offshore platform located at Campeche Bay in the Gulf of Mexico. The optimization criterion includes the reconstruction of the platform. Results indicate that if the first maintenance action is made in 5 years after installing the structure, the second repair action should be made in the following 7 to 10 years; however, if the first maintenance action is made in 6 years after installing the structure, then the second should be made in the following 5 to 8 years.

\section{Introduction}

Structures are continually exposed to different environmental loads that modify both their mechanical properties and their structural performance over time. Due to these modifications, it is useful to formulate maintenance plans for the structural systems. Several approaches of maintenance plans have been proposed in the literature considering different numbers of optimization objectives: that is, (a) minimizing the expected cumulative maintenance cost over a time interval (as a single objective) [1], (b) minimizing maintenance cost and maximizing load-carrying capacity and durability (as two independent objectives) [2], and (c) more powerful approaches that optimize several objectives simultaneously [3-6].

In this paper a multiobjective optimization approach is proposed. Such approach considers a balance among the following objectives: (1) reliability, expressed in terms of the confidence factor that takes into account the structural deterioration over time by means of closed-form mathematical expressions, (2) damage index, expressed in terms of the ratio between the structural capacity and the structural demand, and (3) expected cumulative total cost, which considers costs of inspection, repair, and failure. The optimization problem is solved by means of the elitist Nondominated Sorting Genetic Algorithm (NSGA II) [7] which gives place to a set of nondominated solutions that are used to recommend time intervals for making decisions for maintenance of an offshore structure.

For the particular case of offshore structures, the structural deterioration phenomenon is mainly due to fatigue caused by waves acting continuously on the steel elements. The decrease of the resistance of the structural capacity over a time interval is caused by the cracking of the tubular joints. The inspection of an offshore structural system has two objectives: (a) to detect both the presence and the size increase of cracks and (b) to perform the necessary maintenance actions to the structure accordingly. Many authors have proposed inspection and maintenance plans for offshore structures using different approaches such as the following: (a) the analysis of risk and reliability of welded connections subject to fatigue [8-10]; (b) the use of methodologies that 
take into account a fatigue sensitivity analysis in steel joints [11]; (c) the application of probabilistic detection methods in order to study the influence of repetitive inspection for fatigue in joints [12]; (d) the implementation of simplified approaches and the use of practical design parameters such as fatigue design factors [13] and/or reserve strength ratios [14]; (e) the consideration of damage caused by fatigue, buckling, and dents on structural elements [15], and (f) the use of Bayesian techniques [16].

However, neither a multiobjective criterion for making decisions of maintenance actions on "jacket" marine platforms, nor simplified closed-form mathematical expressions for taking into account the structural deterioration of both structural capacity and structural demand over a time interval are considered in the studies mentioned above, as it is done in the present study. The advantage of using closedform mathematical expressions is the possibility of evaluating the structural reliability without having to perform numerical integrations.

\section{Basic Definitions of Structural Reliability, Damage Index, and Expected Cumulative Total Cost}

2.1. Structural Reliability. The structural reliability can be expressed by means of different indicators, such as probability of failure in a time interval, expected number of failures per unit time, confidence factors, and confidence levelss. In this paper, the confidence factor, $\lambda_{\text {conf }}$, is used as a measure of the reliability implicit in the structure. The confidence factor was originally introduced in order to evaluate the reliability of steel building structures [17-20]. Later, the original methodology was extended to the case in which the mechanical properties of the structural elements present degradation (i.e., due to corrosion, fatigue, etc.), and as a consequence, either the structural capacity or the structural demand, or even both change over time [21-24]. In the present study the confidence factor is evaluated under the assumption that the structural capacity deteriorates linearly over time. For this case, the confidence factor, $\lambda_{\text {conf }}$, is calculated as mentioned in Appendix A.

2.2. Damage Index. The damage index (DI) is defined as the ratio of the structural capacity, $C$, and the structural demand, $D$. The damage index varies between 0 and 1 , where 0 indicates that the structure does not have any damage, and 1 refers to total damage, which means that the structural system has reached its failure condition.

2.3. Expected Cumulative Total Cost. The expected cumulative total cost function is defined as the sum of the expected cost of inspection, repair, and failure, at the end of a time interval $[0, \Delta t)$, as derived in [25] and presented in Appendix B.

\section{Basic Definitions of Genetic Algorithms}

Genetic algorithms (GAs) are adaptive methods used to solve, search, and optimize problems. Based on the principle

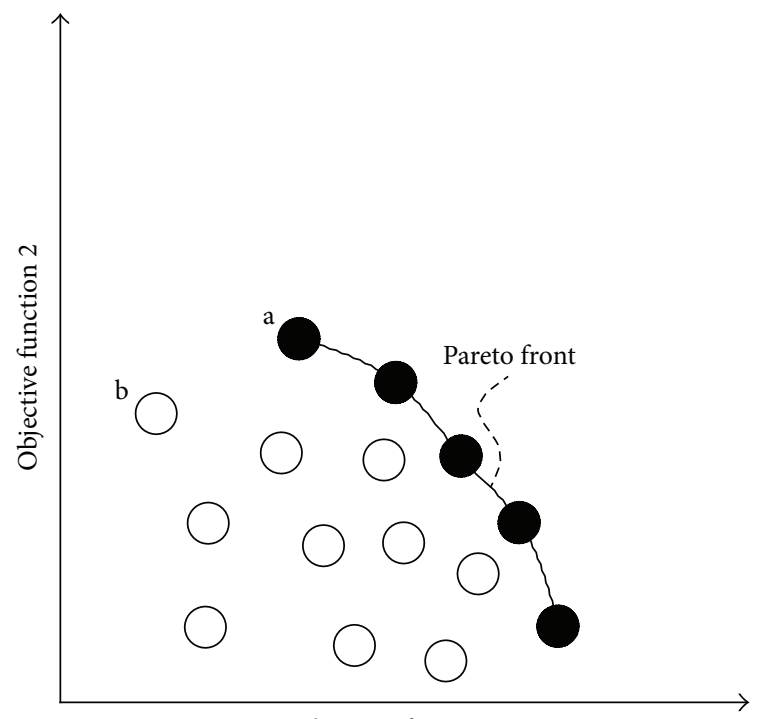

Objective function 1

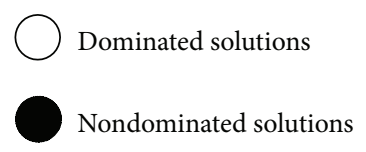

FIGURE 1: Dominated and nondominated solutions.

of the survival of the fittest [26], GAs have been applied successfully in many problems and different areas (i.e., economics, medicine, engineering, etc.). GAs are commonly composed of three basic operators: (1) selection, (2) crossover, and (3) mutation. Recently, GAs have been used by civil engineers due to the ease of handling multiple goals directly and simultaneously $[27,28]$. In this study, GAs are selected as a tool of optimization in order to solve a problem in which three objectives must be satisfied. Commonly, in multiobjective optimization a set of nondominated solutions is obtained, all of which form a Pareto front. The concept of dominance is as follows [29].

Assuming that all objective functions are to be maximized (see Figure 1), it is said that the solution $b$ is dominated by solution $a$ if conditions 1 and 2 are true.

(1) Solution $a$ is not worse than $b$ considering all the objectives.

(2) Solution $a$ is strictly better than $b$ in at least one objective.

In order to find a Pareto front that helps the decisions makers to formulate plans of maintenance of offshore structures which present structural degradation over a time interval, the elitist NSGA II method [7] was used in the present study. The approach consists of the following steps:

(1) Randomly create an initial population $P_{i}$ of size $N$, where $i=$ generation index $(i=0,1,2, \ldots, n)$.

(2) Selection, crossover, and mutation are made to create the offspring population $Q_{i}$ of size $N$.

(3) Combine parent, $P_{i}$, and offspring, $Q_{i}$, to create the population $R_{i}$ of size $2 N$. 
(4) A fast nondominated sort of size $R_{i}$ is made to create the population $P_{i+1}$ of size $N$.

(5) Repeat the process from the second step using the population selected above to create the offspring population, $Q_{i+1}$.

The offspring population $Q_{i}$ is obtained using binary tournament selection, intermediate crossover, and Gaussian mutation. These concepts are explained below.

Binary Tournament Selection. $n$ individuals (commonly 2) are selected randomly from the size population. The selected individuals compete against each other. The individual with the highest fitness win, and it will be included for crossover and mutation [30].

Intermediate Crossover. It is the process of creating offsprings by a weighted average of the parents, and it is controlled by the following ratio $[31,32]$ :

$$
\text { Offspring }=\text { parent } 1+\operatorname{ratio}(\text { parent } 2-\text { parent } 1) .
$$

The value of "ratio" is commonly assumed equal to 1.2 [32].

Gaussian Mutation. It consists in adding a random number taken from a Gaussian distribution with mean 0 to each entry of the parent vector. The standard deviation $(\sigma)$ is determined by the parameters "scale" and "shrink," as follows:

$$
\sigma=\operatorname{scale}\left(1-\operatorname{shrink}\left(\frac{k}{n}\right)\right),
$$

where the "scale" parameter determines the standard deviation at the first generation; the "shrink" parameter controls how the standard deviation shrinks as generations go by; $k$ is the current generation, and $n$ represents the number of total generations under consideration. The values of "scale" and "shrink" are commonly assumed equal to 1.0 [32].

Fast Nondominated Sort. A "naive and slow" procedure [29] is applied in order to sort a population into different nondomination levels. In this procedure each solution is compared with every other solution in order to find out if it is dominated by any other solution in the population. When the comparisons of each solution are completed, all individuals in the first nondominated front are found. All individuals obtained in the first nondominated front are set apart temporarily in order to find the second nondominated front, and the procedure is repeated. The third nondominated front is obtained by setting apart temporarily all the individuals in the first and second front, and the procedure mentioned above is repeated. In summary, different fronts $F=\left(F_{1}, F_{2}, \ldots, F_{n}\right)$ are obtained in this approach, where $F_{1}$ is the best nondominated set, $F_{2}$ is the next best nondominated set, and so on. In case of $F_{1}<N$, all members of the set $F_{1}$ are chosen to create the new population $P_{i+1}$; the remaining members are chosen from the subsequent nondominated sets in the order of their ranking $\left(F_{2}, F_{3}, \ldots, F_{n}\right)$. If $F_{1}>N$, the members are chosen using a crowded-comparison operator [29], in descending order and the best solutions needed to fill the population slots are selected.

\section{General Approach of the Multiobjective Optimization for Structural Maintenance}

The multiobjective optimization criterion for maintenance of offshore structures formulated in the present study considers three objectives: confidence factor $\left(\lambda_{\text {conf }}\right)$, damage index (DI), and expected cumulative total cost (E[CTC]). The first two objectives are subjected to the following constraints:

(i) the confidence factor is subject to $\lambda_{\text {conf }} \geq 1$,

(ii) the damage index is subject to DI $\leq d_{0}$.

That is, the structural reliability expressed in terms of the confidence factor, $\lambda_{\text {conf }}$, must be greater than unity [18] (values less than 1 consider that the structure is in the unsafe side). The damage index (DI) should be smaller or equal to a given threshold $\left(d_{0}\right)$ which is related to a permissible level of structural damage.

The procedure to obtain the set of nondominated solutions is divided here in two general steps: (a) the simulation of values of the three objectives ( $\lambda_{\text {conf }}$, DI, and E[CTC]) over a time interval, as indicated in the flowchart of Figure 2, and (b) the codification of the simulations, to perform the multiobjective optimization by means of NSGA II.

The simulation profiles are codified in order to perform the multiobjective optimization by using the GA mentioned in the previous section. Then, the optimization problem is solved as follows:

(1) maximize the minimum confidence factor;

(2) minimize the maximum damage index;

(3) minimize the expected cumulative total cost.

As a result, a set of nondominated solutions is found for making decisions and for establishing different time interval for maintenance. In this study, the criterion for selecting the maintenance time interval is based on a threshold value of the confidence factor. When the confidence factor takes values between a certain range of values of the nondominated solutions, maintenance actions should be performed. The range of values $\lambda_{\text {conf }}$ to select the repairing time interval is as illustrated in Figure 3, where the nondominated solutions in the bracket are those selected for repairing actions.

Here it is assumed that after several nondominated solutions are selected for maintenance actions, the critical structural elements are repaired to recover their initial capacities, and a new set of nondominated solutions can be obtained after reconstruction. Then, a second set of nondominated solutions is obtained following the flowchart shown in Figure 2 (as done previously); however, an initial cumulative damage (ICD) is now taken into account for the second set of critical structural elements to be analyzed. It is noticed that in the example presented in Section 5 the second set of critical structural elements is different from the first set analyzed in the first step. For illustrative purposes, Figures 4(a), 4(b), and 4(c) show projections of one selected solution (indicated with circles) corresponding to the first maintenance time interval, as well as one solution (indicated with triangles) corresponding to the second time interval for structural maintenance. 


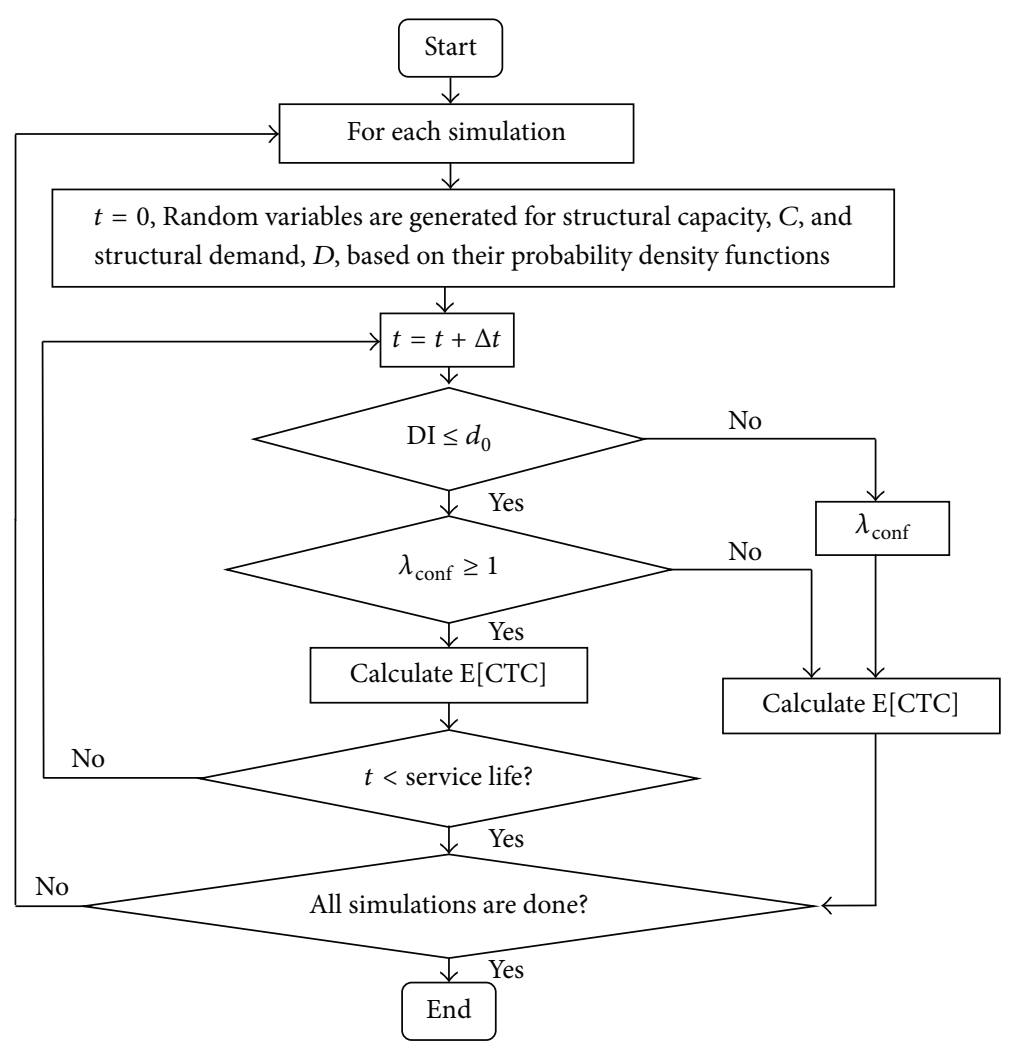

FIGURE 2: Flowchart corresponding to the three objectives simulation.

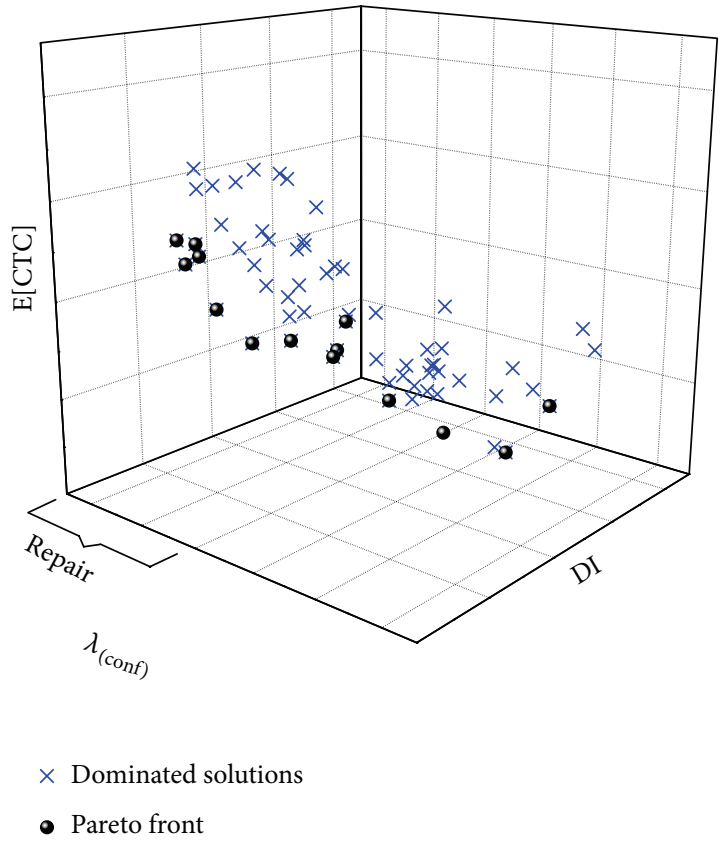

FIgURE 3: Criterion to select repairing time intervals.

\section{Illustrative Example}

The multiobjective approach proposed above is applied to an offshore "jacket" platform with the aim of finding its first and its second time interval for maintenance. The platform is supposed to be located in Campeche Bay. The structure is $48 \mathrm{~m}$ high and the water depth at the site is $45.11 \mathrm{~m}$ (see Figure 5). The expected weight of the deck was assumed equal to 500 ton. The "jacket" platform is represented by a simplified 2D model with mean mechanical properties. The joints were selected according to their global structural capacity contribution. Joints 1, 2, 3, 4, and 6 were selected for finding the first time interval for maintenance, whereas joints $5,7,8$, and 9 were selected for finding the second time interval (once the joints 1,2, 3, 4, and 6 were totally reconstructed).

5.1. Evaluation of Structural Capacity over Different Time Intervals. The lateral resistance of the structure was obtained by means of nonlinear static analyses using twenty different simulated profiles of lateral loads. These profiles are related to the acting forces corresponding to the simulated waves that produced the maximum base shear on the structure. The appearance and growth of cracks, which give place to a reduction of the structural capacity, are considered as damage condition. Two crack points were considered for each structural element connected to the joints.

The average crack size simulation process of the selected points subject to random load was performed using the Monte Carlo technique. Operational and storm waves were considered. The arrival times between storms were assumed with exponential distribution. The storm wave heights follow a Gumbel distribution. The statistical parameters used for simulation of the crack size were taken from Silva and 


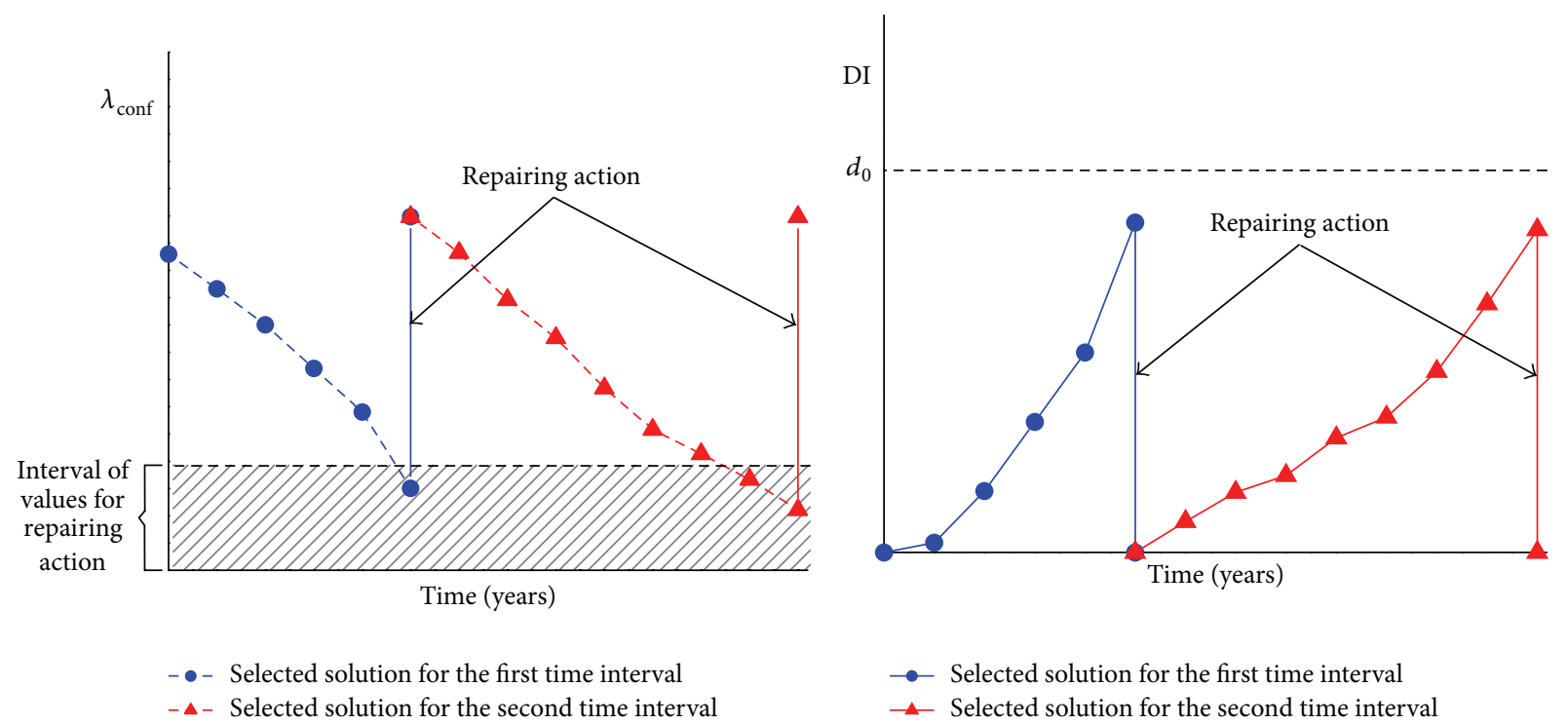

(a)

(b)

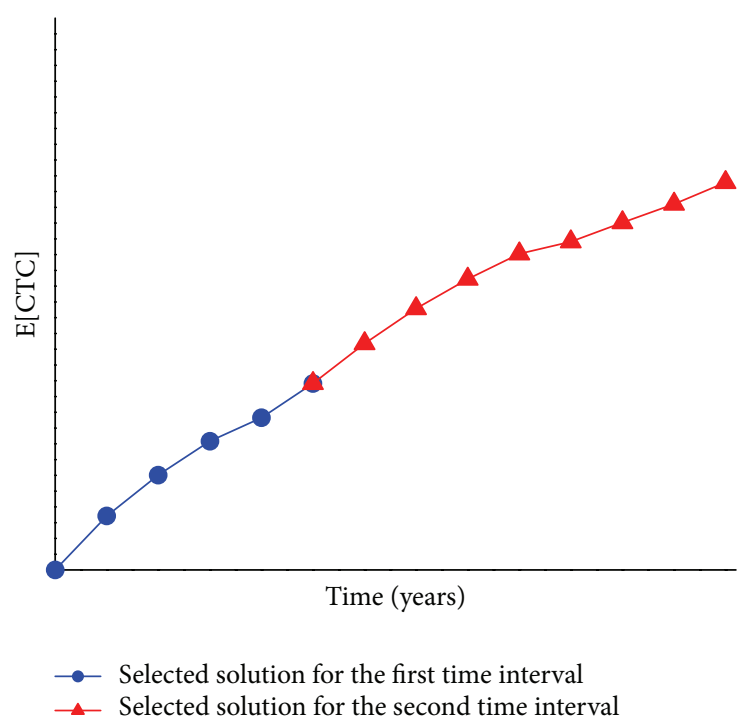

(c)

FIGURE 4: Projections of selected solutions corresponding to the first and second time intervals for repairing actions.

Heredia [33]. The crack size was obtained using the modified differential equation by Paris and Ergodan [34] and Sobczyk and Spencer [35]. In the differential equation, the random load was replaced by an equivalent cyclic load whose amplitude and frequency were expressed in terms of the mean properties of the random process. After obtaining the time history of the crack size, the capacity of the joint was reduced by a linear correction factor as follows $[36,37]$ :

$$
P_{c}=P_{k}\left(1-\left(\frac{A_{\text {crack }}}{A_{\text {joint }}}\right)\right),
$$

where $P_{c}$ is the capacity of the cracked joint; $P_{k}$ is the capacity of the intact joint which can be calculated by means of the API recommendations [38]; $A_{\text {joint }}$ and $A_{\text {crack }}$ are the areas of the transverse section and of the crack, respectively, corresponding to all the elements connected to the joint. As an example, percentages of simulated cracked areas at the end of different time intervals, corresponding to joint 2 , are shown in Figure 6.

The median of structural capacity, $\widehat{C}$, represented in terms of the global displacement (in meters, m) of the platform, and the standard deviation of its natural logarithm, $\sigma_{\ln C \mid \Delta t}$ are shown in Table 1 for different time intervals $(\Delta t=$ $0,1,2, \ldots, 15$ years). It is assumed that both the structural capacity and the structural demand follow a lognormal distribution in any time [17-21].

5.2. Evaluation of the Structural Demand over Different Time Intervals. The structural demand (given a maximum wave height) at the end of a time interval was obtained by means 


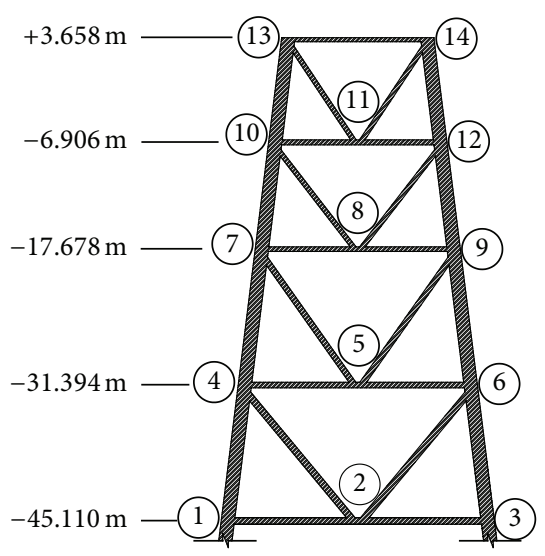

Figure 5: 2D model of the "jacket" platform.

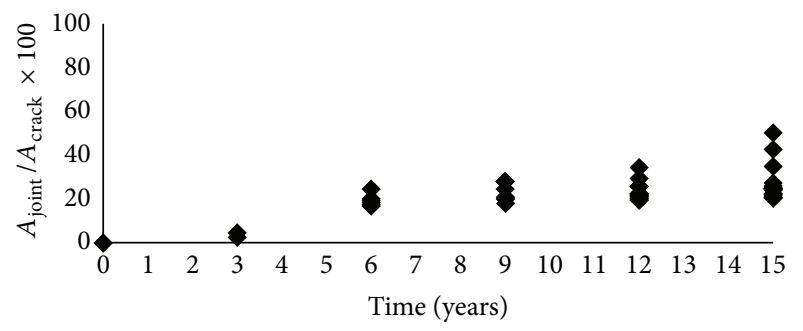

FIgURE 6: Percentages of simulated cracked areas. Joint 2.

TABLE 1: Median of structural capacity, $\widehat{C}$, and standard deviation of the natural logarithm of the structural capacity at different time intervals.

\begin{tabular}{lll}
\hline$\Delta t$ (years) & $\widehat{C}(\mathrm{~m})$ & $\sigma_{\ln C \mid \Delta t}$ \\
\hline 0 & 0.2520 & 0.0140 \\
1 & 0.2516 & 0.0574 \\
2 & 0.2492 & 0.0901 \\
3 & 0.2462 & 0.1054 \\
4 & 0.2429 & 0.1130 \\
5 & 0.2378 & 0.1500 \\
6 & 0.2322 & 0.1813 \\
7 & 0.2297 & 0.1902 \\
8 & 0.2272 & 0.1918 \\
9 & 0.2206 & 0.1971 \\
10 & 0.2190 & 0.1978 \\
11 & 0.2179 & 0.2079 \\
12 & 0.2151 & 0.2122 \\
13 & 0.2116 & 0.2137 \\
14 & 0.2106 & 0.2305 \\
15 & 0.2092 & 0.2334 \\
\hline
\end{tabular}

of dynamic "step by step" analysis, using simulated time histories of waves that correspond to different maximum wave heights. The crack growth simulations and the capacity reductions at selected joints considered to evaluate the capacity $\widehat{C}$ over time (Section 5.1) were also used in this section as damage condition. Figures $7(a)$ and $7(b)$ show the median structural demand as a function of the platform global displacement, and the corresponding standard deviation of the natural logarithm of the demand, for different intervals $\Delta t$, respectively. The expression that fits the median values of the structural demand, $\widehat{D}$, given a maximum wave height, $h_{\max }$, at the end of different time intervals $\Delta t$, is given by $\widehat{D}(\Delta t)=(a+f \cdot \Delta t) \cdot h_{\max }^{b}$ (a similar expression was proposed by Tolentino et al. [24]). According to the above, the median structural demand, given a maximum wave height, is equal to $\widehat{D}(\Delta t)=(3.75 E-04+5.0 E-08 \cdot \Delta t) \cdot h_{\max }^{2.0}$. Similarly, the corresponding standard deviation of the natural logarithm of the demand is given by $\sigma_{\ln D \mid h_{\max }, \Delta t}=(1.65 E-03+1.5 E-05$. $\Delta t) \cdot h_{\max }^{1.5}$.

5.3. Damage Index. In this study the damage index is defined as follows:

$$
\mathrm{DI}=\frac{C_{0}-C(\Delta t)}{C_{0}-D(\Delta t)},
$$

where $C_{0}$ is the maximum global displacement of the structure without damage, $C(\Delta t)$ represents the maximum global displacements that consider structural deterioration at instant $\Delta t$, and $D(\Delta t)$ is the ultimate global displacement demanded by the structure at instant $\Delta t$.

5.4. Confidence Factor and Expected Cumulative Total Cost. The confidence factor values, $\lambda_{\text {conf }}(0, \Delta t)$, were calculated using (A.1). The parameters $\alpha$ and $\beta$ were fitted according to (A.4), based on the median values of the structural capacity, $\widehat{C}$, shown in Table 1. The epistemic uncertainties associated with the structural demand, $\sigma_{U D}$, and with the structural capacity, $\sigma_{U C}$, were assumed equal to 0.15 . The parameters $k$ and $r$ fitted to the wave hazard curve were equal to $k=5.0 E 03$ and $r=5$, which correspond to a maximum wave height equal to $h_{\max }=23 \mathrm{~m}$ and to a return interval of 1485 years for the failure condition [39].

The expected cumulative total cost was evaluated using (B.1). An annual discount rate $\gamma=6 \%$ was assumed. The inspection cost by joint was 3,518 USD [40] and the repair cost was 20,000 USD for each critical point [41]. The cost of failure includes costs due to equipment damage, pollution, deferred production, and indirect losses [25].

5.5. Simulation of the Three Objectives. 1024 profiles of damage index, confidence factor, and expected cumulative total cost, considering cumulative damage at the end of a time interval $[0, \Delta t)$, were simulated, following the procedure presented in Figure 2. The simulations were based on the median values and the standard deviations of structural capacity and structural demand. Lognormal distribution functions were assumed.

5.6. Multiobjective Optimization before Reconstruction (First Time Interval for Maintenance). The simulations were codified in order to perform the optimization by means of NSGA II. A population size of 50 was considered. A set of 12 optimal solutions in 24 generations were found. Different views of 


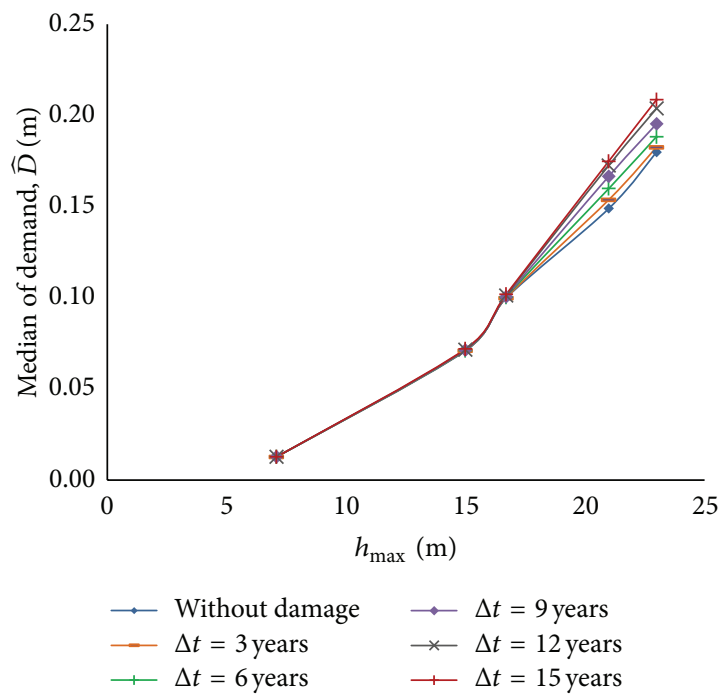

(a)

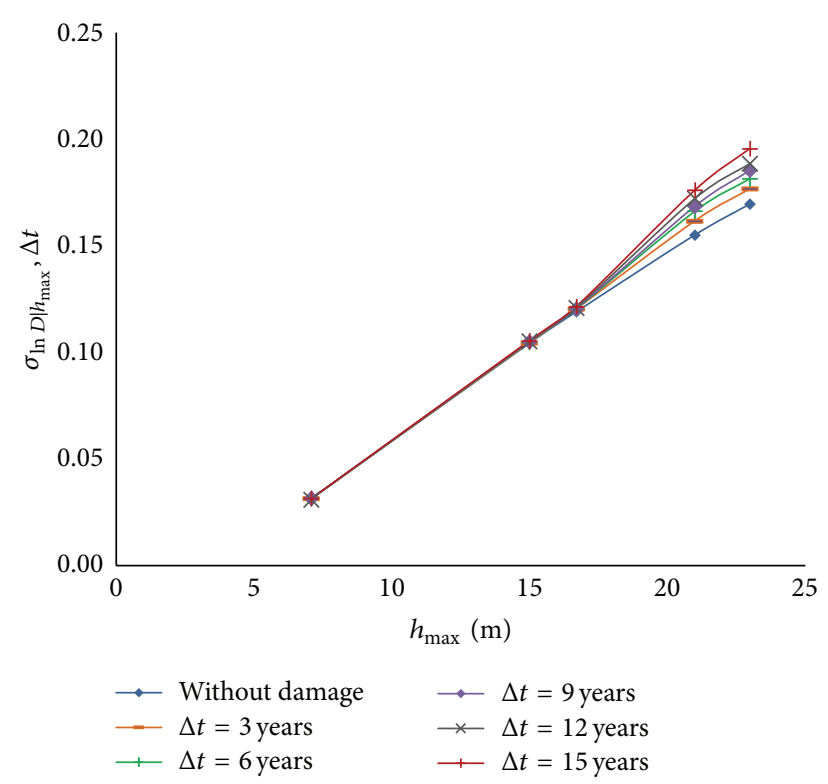

(b)

Figure 7: (a) Median of structural demand and (b) standard deviation of the natural logarithm of the demand, for different time intervals.

TABLE 2: Comparison between solutions A, B, C, D, E, and F.

\begin{tabular}{|c|c|c|c|c|}
\hline Solution & $\begin{array}{l}\text { Time interval } \\
\text { (years) }\end{array}$ & $\begin{array}{l}\text { Damage index } \\
\text { (DI) }\end{array}$ & $\begin{array}{c}\text { Confidence factor } \\
\left(\lambda_{\text {conf }}\right)\end{array}$ & $\begin{array}{c}\text { Expected cumulative } \\
\text { total cost E[CTC] } \\
\text { (USD) }\end{array}$ \\
\hline$A$ & 6 & 0.2345 & 1.0965 & 1105415 \\
\hline B & 5 & 0.2387 & 1.1375 & 930566 \\
\hline $\mathrm{C}$ & 5 & 0.2421 & 1.1452 & 850778 \\
\hline $\mathrm{D}$ & 4 & 0.2762 & 1.2246 & 786761 \\
\hline $\mathrm{E}$ & 4 & 0.2879 & 1.2381 & 818191 \\
\hline $\mathrm{F}$ & 3 & 0.2939 & 1.2378 & 665032 \\
\hline
\end{tabular}

the Pareto front that include damage index, confidence factor, and the expected total cost over a time interval are shown in Figures 8(a), 8(b), and 8(c). Figure 8(d) shows the same results in $3 \mathrm{D}$ view. It can be observed that the damage index varies between 0.23 and 0.29 , the confidence factor presents values between 1.10 and 1.24, and the expected cumulative total cost takes values between $6.62 E+05$ and $1.10 E+06$ USD. In order to compare different time intervals to perform maintenance actions, six optimal solutions (A, B, C, D, E, and F) were selected (see Figures $8(\mathrm{a})-8(\mathrm{~d})$ ). A comparison among the solutions selected is shown in Table 2 .

With the aim of establishing time intervals of structural maintenance, solutions associated with values of $\lambda_{\text {conf }} \leq$ 1.15 were selected for repairing actions. Then, in accordance to Table 2, maintenance actions on joints $1,2,3,4$, and 6 should be performed between 5 and 6 years (corresponding to solutions $\mathrm{A}, \mathrm{B}$, and $\mathrm{C}$ ).

\subsection{Multiobjective Optimization after Reconstruction (Second} Time Interval for Maintenance). In this section it is assumed that the maintenance (repairing) actions on joints 1, 2, 3, 4 , and 6 are performed in accordance with solution $A$, and alternatively, with solution $\mathrm{C}$. It means that the first repair is done after 6 years of installing the platform (solution A), or alternatively, after 5 years if solution $\mathrm{C}$ is selected (see Table 2). Also, it is considered that after maintenance, the joints recover their full capacity. Taking this into account, the joints that should be repaired in the next maintenance plan are joints $5,7,8$, and 9 (which were selected in accordance with their contribution to global structural capacity).

The evaluation of the structural capacity and the structural demand (given a maximum wave height) at the end of a time interval $[0, \Delta t)$, after the first maintenance action, was performed in a similar way as in Sections 5.1 and 5.2; however, it was now considered that joints $5,7,8$, and 9 presented an initial cumulative damage (ICD). The ICD takes into account the deterioration due to fatigue that the joints suffered during the time interval between the installation of the structure and its first repair. Figure 9 shows an example of the percentages of cracked areas of joint 5 at the end of different time intervals, considering an ICD corresponding to 5 years (which is associated with solution C). It is noticed that in Figure 9 there is an initial cumulative damage (represented by $A_{\text {joint }} / A_{\text {crack }} \times 100$ ) at $\Delta t=0$ years (on the contrary, 


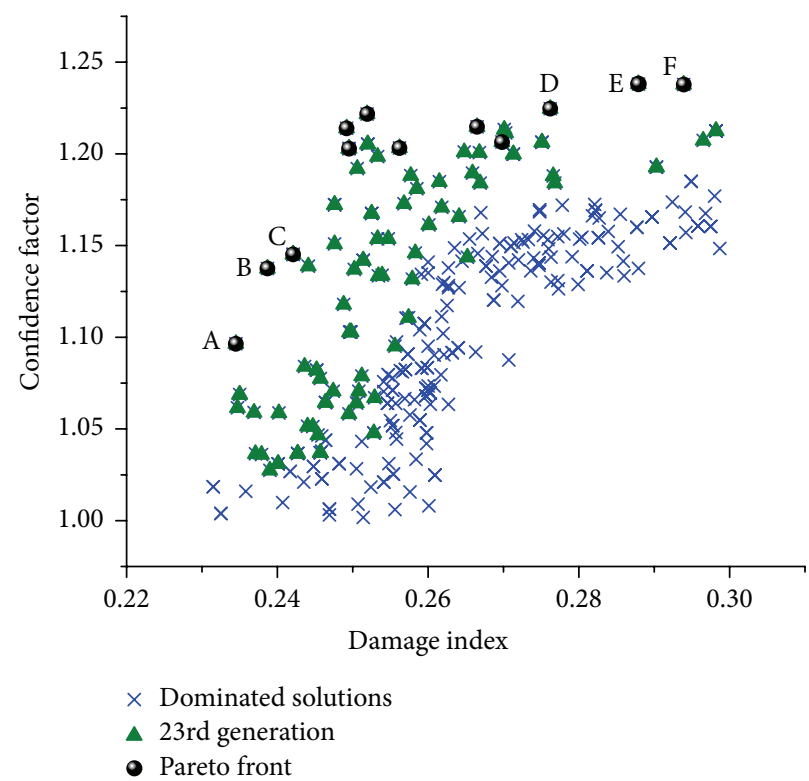

(a)

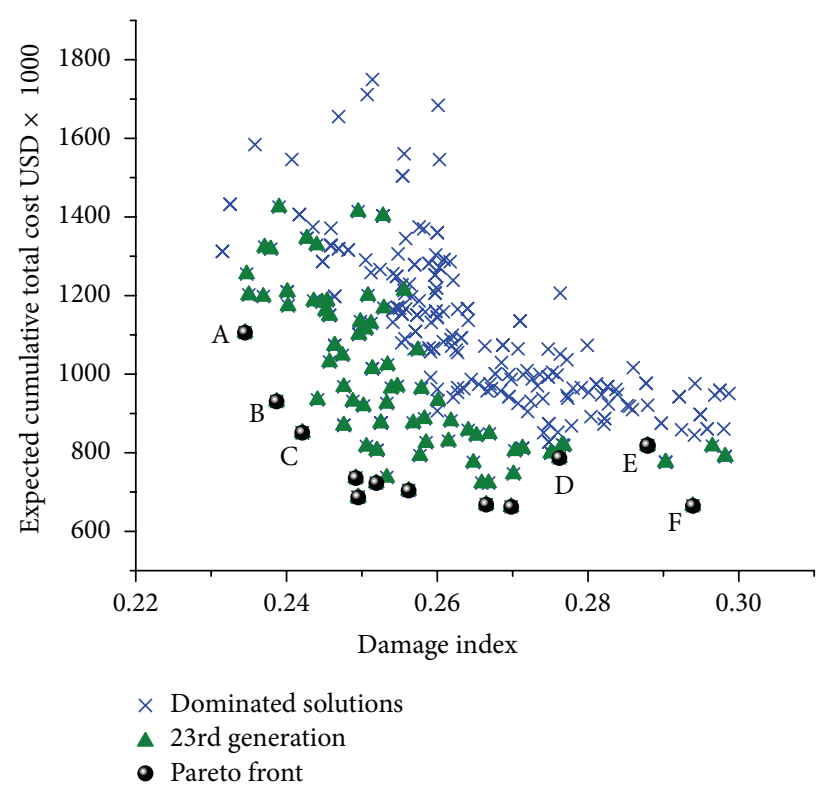

(c)

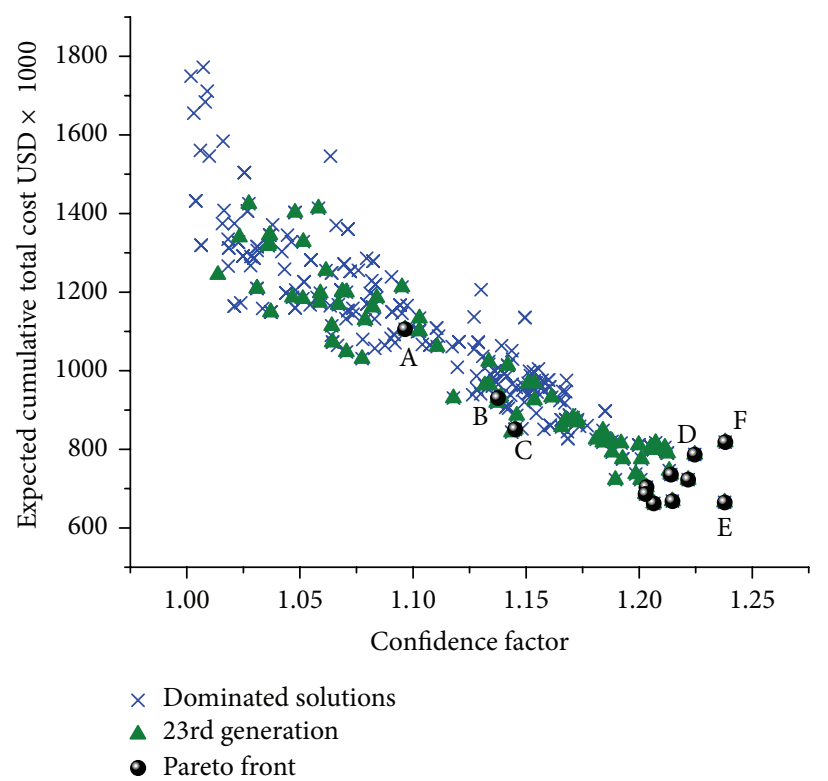

(b)

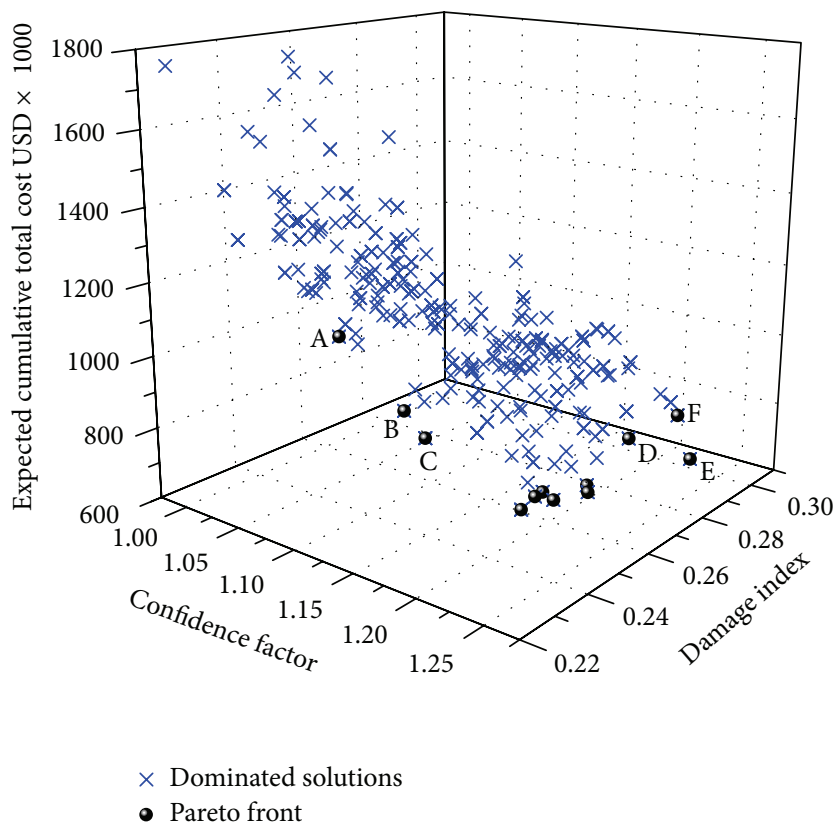

(d)

Figure 8: Pareto front corresponding to the three objective functions and optimal solutions A, B, C, D, E, and F.

Figure 6 does not indicate any initial cumulative damage in joint 2).

Tables 3 and 4 show the median of the structural capacity, $\widehat{C}$, represented in terms of global displacement of the platform, corresponding to solutions $\mathrm{A}$ and $\mathrm{C}$, respectively, for different time intervals $(\Delta t)$ after the first maintenance actions. The standard deviations of the natural logarithm of the structural capacity are also shown in Tables 3 and 4.

The median of the structural demand (given a maximum wave height, $\left.h_{\max }\right)$ was calculated as in Section 5.2. The expressions obtained are $\widehat{D}(\Delta t)=(3.55 E-04+4.1 E-08$. $\Delta t) \cdot h_{\max }^{2}$ and $\widehat{D}(\Delta t)=(3.4 E-04+4.0 E-08 \cdot \Delta t) \cdot h_{\max }^{2}$, for solutions $\mathrm{A}$ and $\mathrm{C}$, respectively. The standard deviations of the natural logarithm of the demand, for a maximum wave height, at the end of different time intervals $(\Delta t)$ were fitted as $\sigma_{\ln D \mid h_{\max } \Delta t}=(1.5 E-03+1.5 E-05 \cdot \Delta t) \cdot h_{\max }^{1.55}$ and $\sigma_{\ln D \mid h_{\max }, \Delta t}=(1.4 E-03+1.4 E-05 \cdot \Delta t) \cdot h_{\max }^{1.55}$ for solutions $A$ and $\mathrm{C}$, respectively.

A total of 1024 simulations corresponding to solution A, and alternatively, to solution $\mathrm{C}$ were performed following the procedure presented in Figure 2. The simulations were 


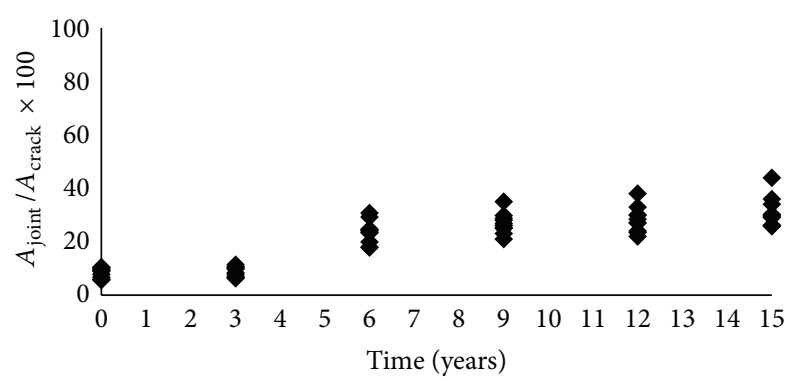

FIGURE 9: Percentages of the simulated cracked area on joint 5, with an ICD corresponding to solution C.

TABLE 3: Median of the structural capacity, $\widehat{C}$, and standard deviation of the natural logarithm, at the end of different time intervals, corresponding to solution A.

\begin{tabular}{lcc}
\hline$\Delta t$ (years) & $\widehat{C}(\mathrm{~m})$ & $\sigma_{\ln C \mid \Delta t}$ \\
\hline 0 & 0.2530 & 0.0129 \\
1 & 0.2515 & 0.0336 \\
2 & 0.2499 & 0.0885 \\
3 & 0.2474 & 0.1141 \\
4 & 0.2448 & 0.1412 \\
5 & 0.2420 & 0.1592 \\
6 & 0.2373 & 0.1803 \\
7 & 0.2365 & 0.1870 \\
8 & 0.2325 & 0.1966 \\
9 & 0.2304 & 0.2026 \\
10 & 0.2296 & 0.2033 \\
11 & 0.2286 & 0.2193 \\
12 & 0.2249 & 0.2176 \\
13 & 0.2246 & 0.2247 \\
14 & 0.2227 & 0.2362 \\
15 & 0.2213 & 0.2578 \\
\hline
\end{tabular}

codified for each case in order to realize the optimization procedure using NSGA II. A population size of 50 was considered. A set of 13 optimal solutions with 23 generations for solution A was found, and 12 optimal solutions with 25 generations for solution $\mathrm{C}$ were obtained. Figures 10 and 11 show the set of solutions (Pareto fronts) for cases A and C, respectively. Next, some optimal solutions are selected in order to handle different options for structural maintenance. A comparison of two sets of solutions selected is shown in Tables 5 and 6 (see Figures 10 and 11).

In a similar way to the previous section, the time intervals for the second maintenance actions are performed when the structural confidence values are lower than 1.15. Tables 5 and 6 show that maintenance actions could be done at time intervals between 5 and 8 years (solutions $a_{1}, b_{1}, c_{1}$, and $d_{1}$ ) if the first maintenance actions were done after 6 years of installing the platform, or alternatively, at intervals between 7 and 10 years (solutions $\mathrm{a}_{2}, \mathrm{~b}_{2}, \mathrm{c}_{2}$, and $\mathrm{d}_{2}$ ) if the
TABLE 4: Median of the structural capacity, $\widehat{C}$, and standard deviation of the natural logarithm, at the end of different time intervals, corresponding to solution C.

\begin{tabular}{lll}
\hline$\Delta t$ (years) & $\widehat{C}(\mathrm{~m})$ & $\sigma_{\ln C \mid \Delta t}$ \\
\hline 0 & 0.2534 & 0.0146 \\
1 & 0.2518 & 0.0383 \\
2 & 0.2503 & 0.0863 \\
3 & 0.2495 & 0.1196 \\
4 & 0.2476 & 0.1250 \\
5 & 0.2468 & 0.1398 \\
6 & 0.2448 & 0.1433 \\
7 & 0.2417 & 0.1509 \\
8 & 0.2392 & 0.1602 \\
9 & 0.2375 & 0.1668 \\
10 & 0.2364 & 0.1702 \\
11 & 0.2342 & 0.1841 \\
12 & 0.2315 & 0.1915 \\
13 & 0.2300 & 0.1920 \\
14 & 0.2285 & 0.2026 \\
15 & 0.2273 & 0.2332 \\
\hline
\end{tabular}

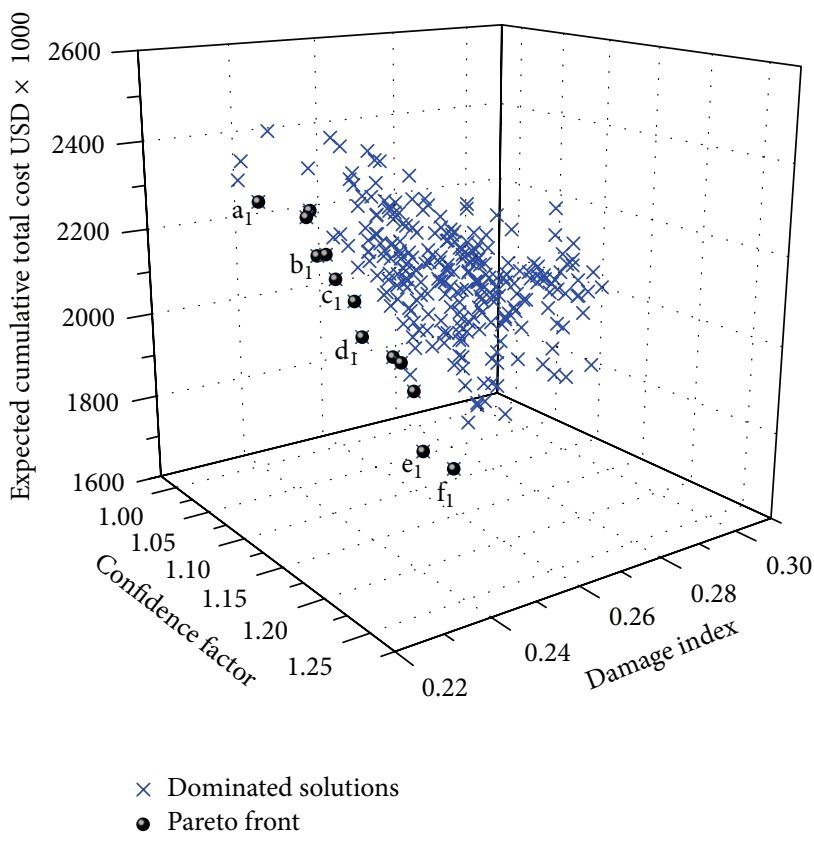

FIgURE 10: Pareto front with 13 optimal solutions considering solution A for the first time interval for maintenance and a set of solutions selected $\left(a_{1}, b_{1}, c_{1}, d_{1}, e_{1}\right.$, and $\left.f_{1}\right)$ for the second interval for maintenance.

first maintenance actions were performed after 5 years of installing the platform.

Figures 12(a), 12(b), and 12(c) show projections of solution A (see Table 2) together with projections of solutions $a_{1}, b_{1}$, $c_{1}$, and $d_{1}$ corresponding to the three objectives (damage index, confidence factor, and expected cumulative total cost). Similarly, Figures 13(a), 13(b), and 13(c) show projections of 
TABLE 5: Comparison between solutions $\mathrm{a}_{1}, \mathrm{~b}_{1}, \mathrm{c}_{1}, \mathrm{~d}_{1}, \mathrm{e}_{1}$, and $\mathrm{f}_{1}$. ICD corresponding to 6 years.

\begin{tabular}{lcccc}
\hline Solution & $\begin{array}{c}\text { Time interval } \\
\text { (years) }\end{array}$ & $\begin{array}{c}\text { Damage index } \\
\text { (DI) }\end{array}$ & $\begin{array}{c}\text { Confidence factor } \\
\left(\lambda_{\text {conf }}\right)\end{array}$ & $\begin{array}{c}\text { Expected cumulative } \\
\text { total cost E[CTC] } \\
(\text { USD) }\end{array}$ \\
\hline $\mathbf{a}_{\mathbf{1}}$ & $\mathbf{8}$ & 0.2277 & $\mathbf{1 . 0 8 5 9}$ & 2319250 \\
$\mathbf{b}_{\mathbf{1}}$ & $\mathbf{7}$ & 0.2388 & $\mathbf{1 . 0 9 3 5}$ & 2190760 \\
$\mathbf{c}_{\mathbf{1}}$ & $\mathbf{6}$ & 0.2435 & $\mathbf{1 . 1 1 1 9}$ & 2095360 \\
$\mathbf{d}_{\mathbf{1}}$ & $\mathbf{5}$ & 0.2448 & $\mathbf{1 . 1 1 3 6}$ & 2014650 \\
$\mathrm{e}_{1}$ & 3 & 0.2489 & 1.1630 & 1794310 \\
$\mathrm{f}_{1}$ & 3 & 0.2535 & 1.1751 & 1756520 \\
\hline
\end{tabular}

TABLE 6: Comparison between solutions $\mathrm{a}_{2}, \mathrm{~b}_{2}, \mathrm{c}_{2}, \mathrm{~d}_{2}, \mathrm{e}_{2}, \mathrm{f}_{2}$, and $\mathrm{g}_{2}$. ICD corresponding to 5 years.

\begin{tabular}{lcccc}
\hline Solution & $\begin{array}{c}\text { Time interval } \\
\text { (years) }\end{array}$ & $\begin{array}{c}\text { Damage index } \\
\text { (DI) }\end{array}$ & $\begin{array}{c}\text { Confidence factor } \\
\left(\lambda_{\text {conf }}\right)\end{array}$ & $\begin{array}{c}\text { Expected cumulative } \\
\text { total cost E[CTC] } \\
(\text { USD) }\end{array}$ \\
\hline $\mathbf{a}_{2}$ & $\mathbf{1 0}$ & 0.2284 & $\mathbf{1 . 0 8 2 7}$ & 2133420 \\
$\mathbf{b}_{2}$ & $\mathbf{9}$ & 0.2309 & $\mathbf{1 . 0 8 8 6}$ & 2040560 \\
$\mathbf{c}_{2}$ & $\mathbf{8}$ & 0.2371 & $\mathbf{1 . 1 2 0 0}$ & 1870170 \\
$\mathbf{d}_{2}$ & $\mathbf{7}$ & 0.2375 & $\mathbf{1 . 1 2 5 5}$ & 1813980 \\
$\mathrm{e}_{2}$ & 5 & 0.2680 & 1.2029 & 1665650 \\
$\mathrm{f}_{2}$ & 4 & 0.2734 & 1.2284 & 1523060 \\
$\mathrm{~g}_{2}$ & 4 & 0.2980 & 1.2458 & 1554500 \\
\hline
\end{tabular}

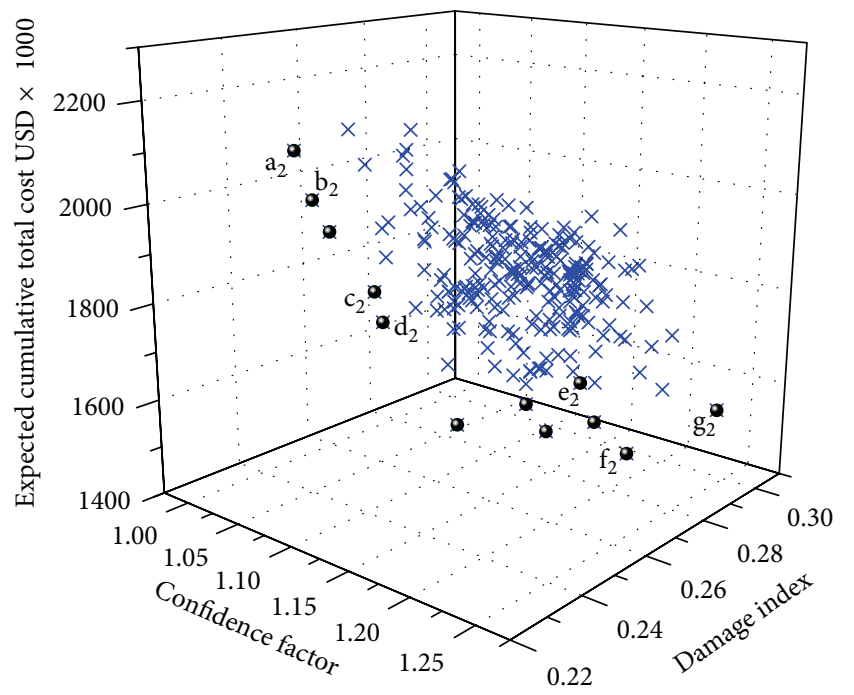

$\times$ Dominated solutions

- Pareto front

FIGURE 11: Pareto front with 12 optimal solutions considering solution $\mathrm{C}$ for the first time interval for maintenance and a set of solutions selected $\left(a_{2}, b_{2}, c_{2}, d_{2}, e_{2}, f_{2}\right.$, and $\left.g_{2}\right)$ for the second interval for maintenance.

solution $\mathrm{C}$ together with projections of solutions $\mathrm{a}_{2}, \mathrm{~b}_{2}, \mathrm{c}_{2}$, and $\mathrm{d}_{2}$.
In summary, in accordance with the criterion selected for performing maintenance actions (values of $\lambda_{\text {conf }}<1.15$ ), Figures 12(a) and 12(b) show that the first optimal time interval for reconstructing joints $1,2,3,4$, and 6 can be after 6 years of installing the offshore "jacket" platform (see Table 2, solution A). If this solution is selected, then the second optimal time interval for repairing actions on joints $5,7,8$, and 9 should be after $5,6,7$, or 8 years (solutions $a_{1}, b_{1}$, $c_{1}$, or $\mathrm{d}_{1}$ ) of reconstructing the structure. On the other hand, if the maintenance actions for the first time are done after 5 years of installing the marine structure (solution C in Table 2), then the repairing actions on joints 5, 7, 8, and 9 should be performed after $7,8,9$, or 10 years after reconstructing the structure (solutions $a_{2}, b_{2}, c_{2}$, or $d_{2}$ ), as shown in Figures 13(a) and 13(b).

\section{Conclusions}

An approach based on multiobjective optimization in order to find adequate time intervals for maintenance, by means of genetic algorithms, is applied. A set of nondominated solutions is found based on three objectives: (1) confidence factor, which is represented by closed-form mathematical expressions that take into account the structural deterioration over time, (2) damage index, expressed in terms of the ratio between the structural capacity and structural demand, and (3) expected cumulative total cost, which considers inspection, repair, and failure costs. 


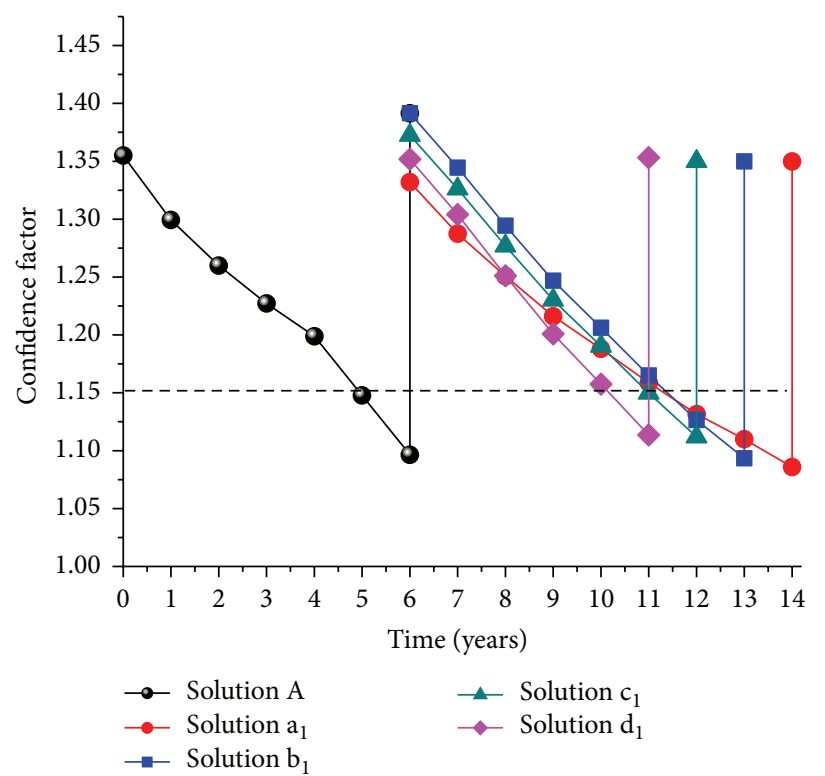

(a)

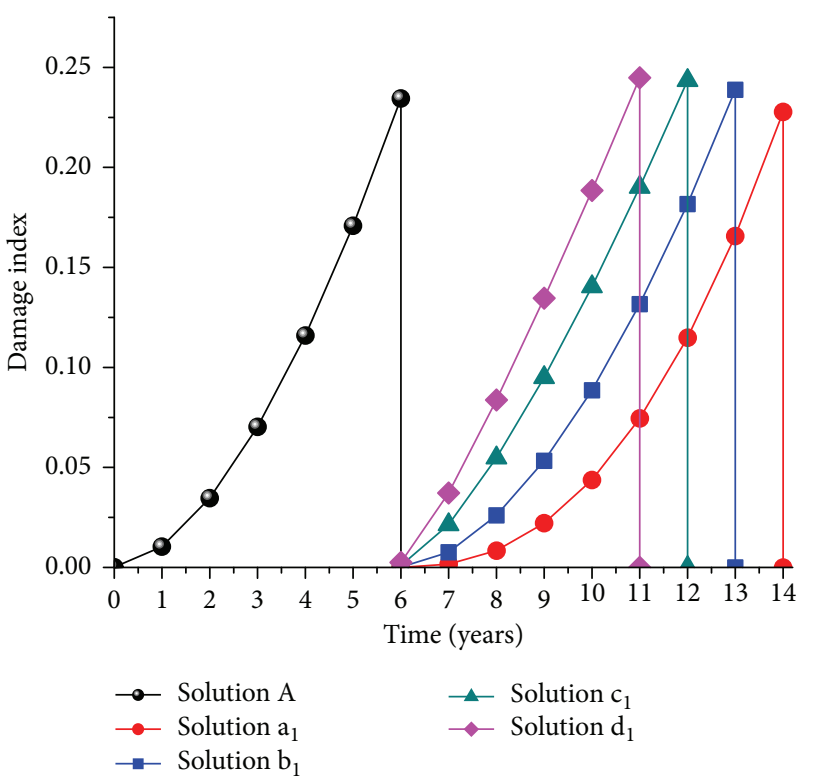

(b)

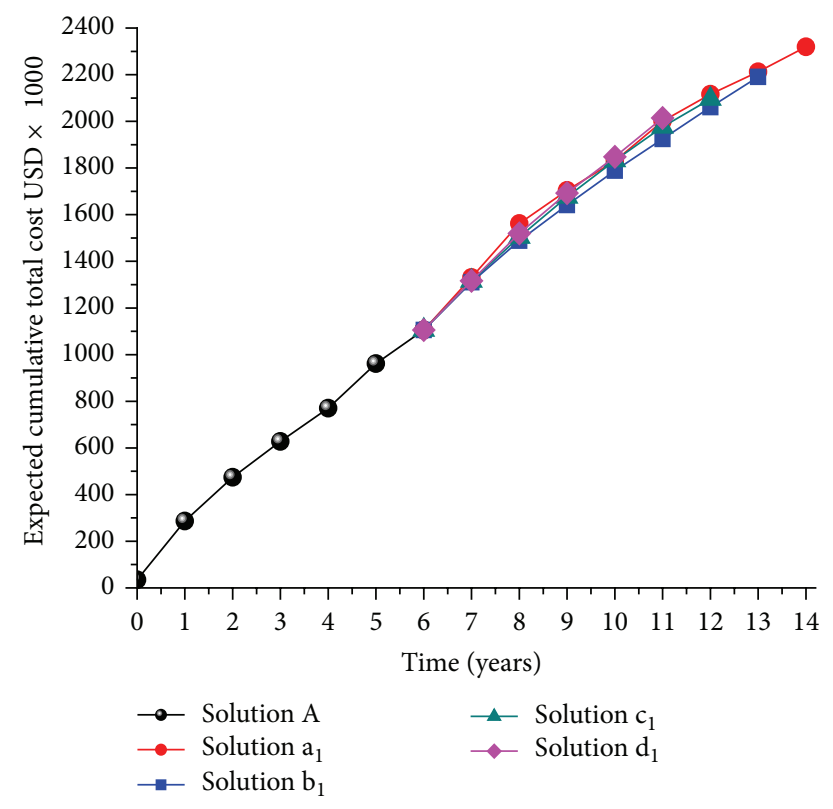

(c)

FIGURE 12: Different projections of solution A and of solutions $a_{1}, b_{1}, c_{1}$, and $d_{1}$.

The evolutionary Nondominated Sorting Genetic Algorithm NSGA II was selected as a tool to solve the optimization problem. Different sets of nondominated solutions were found in order to recommend different time intervals for maintenance actions of a fixed steel "jacket" platform subjected to structural deterioration over time. The implemented GA is very efficient since it only requires a few seconds to find a set of nondominated solutions based on different objectives; it also requires less than 30 generations in order to obtain the Pareto front.

The results show that, for the offshore "jacket" platform analyzed, it is recommended to make the maintenance actions on the first set of selected joints, between 5 and 6 years after installing the platform. In the case of performing the first maintenance action after 5 years, the second time interval for repairing the second set of joints is recommended to be done between 7 and 10 years. On the other hand, if the first maintenance actions are performed after 6 years of installing the platform, the second time interval for maintenance actions should be between 5 and 8 years.

The multiobjective optimization approach presented, together with the closed-form mathematical expression used, constitutes an efficient tool for making maintenance plans for 


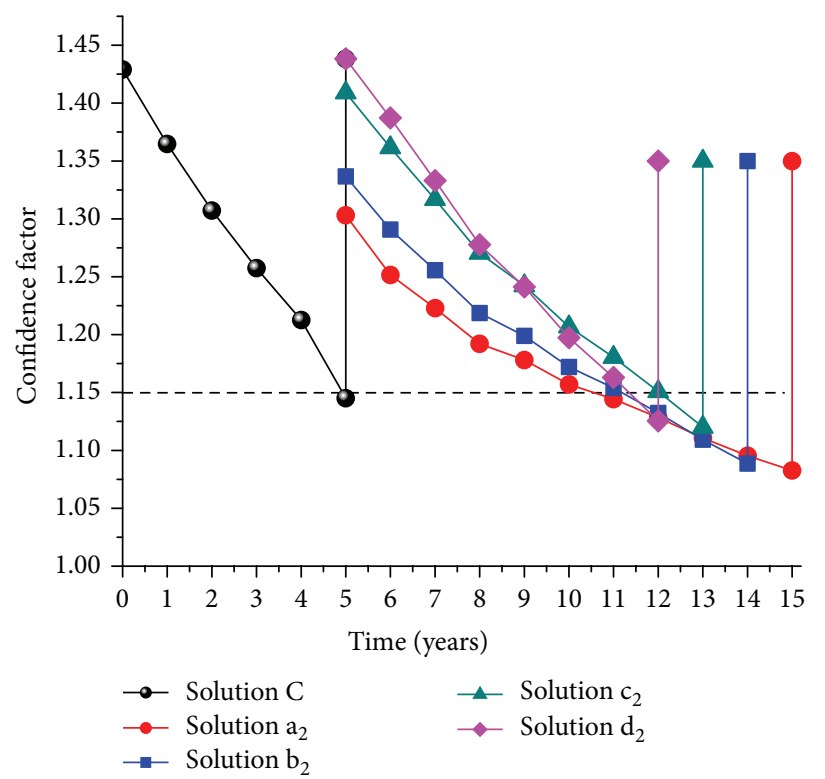

(a)

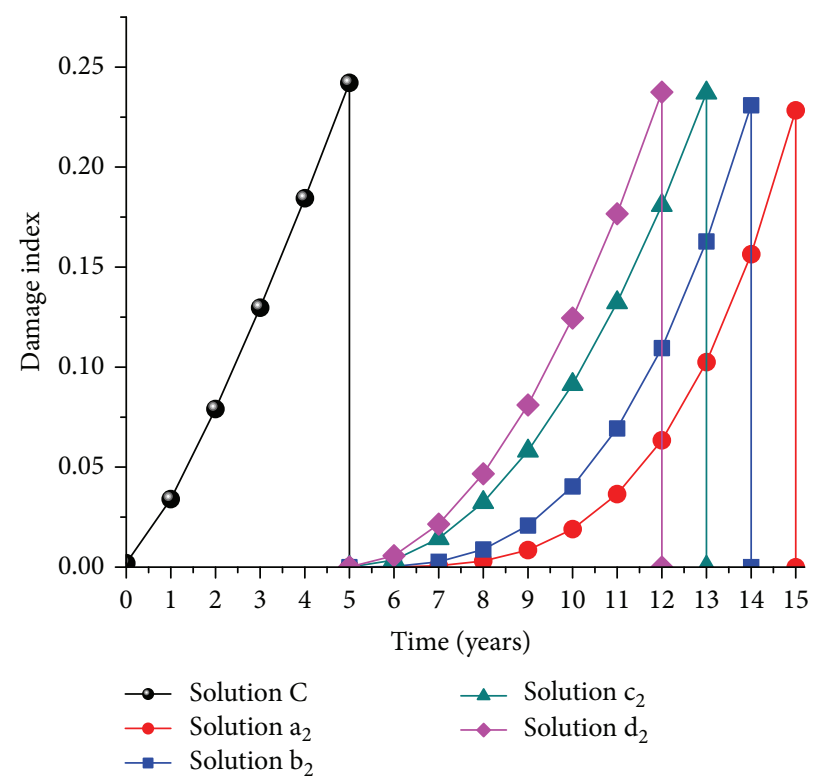

(b)

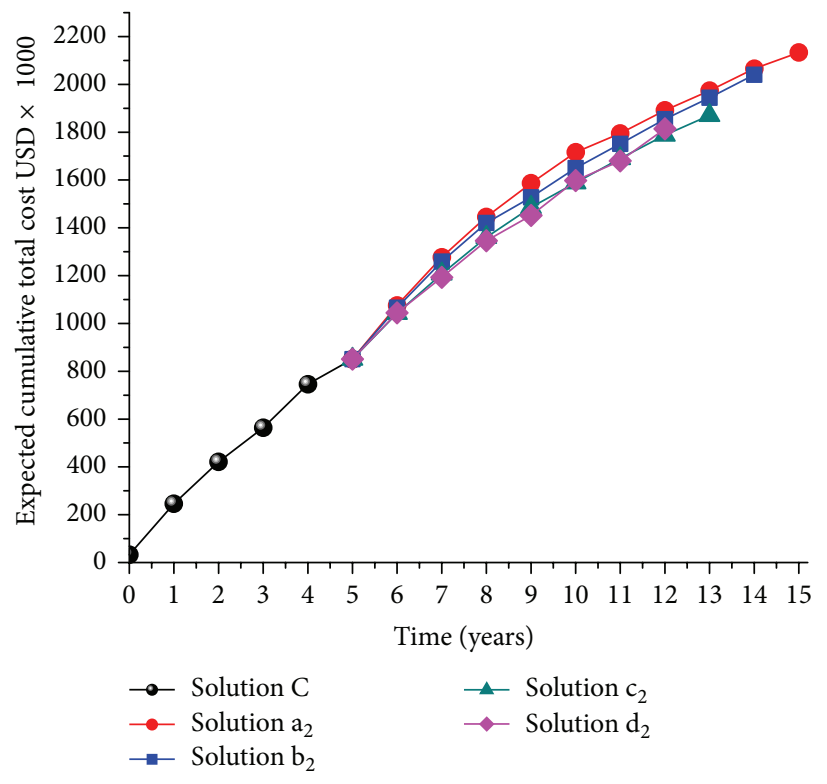

(c)

FIGURE 13: Different projections of solution $C$ and of solutions $a_{2}, b_{2}, c_{2}$, and $d_{2}$.

offshore structures; moreover, it can be adapted to consider different kinds of structures (buildings, transmission towers, bridges, etc.). The criterion can be extended to take into account different types of maintenance actions in order to keep the structural system within prescribed performance levels.

A limitation of the approach presented here is that it is adequate only for making decisions about structural maintenance actions for systems subjected to ordinary excitations; it does not apply to the identification of repair actions that should be taken after the occurrence of extraordinarylinebreak environmental events, for example, after the action of hurricanes with a return period much longer than that considered here (see Section 5.4).

\section{Appendices}

\section{A. Confidence Factor That Takes into Account the Structural Deterioration}

The confidence factor over the time interval $[0, \Delta t)$ can be expressed as follows [21, 24]:

$$
\lambda_{\text {conf }}(0, \Delta t)=\frac{\phi \cdot \widehat{C}}{\gamma \cdot \widehat{D}^{\nu_{0}}}\left[\frac{\Omega(0, \Delta t)}{\Delta t}\right]^{-b / r},
$$


where

$$
\begin{gathered}
\phi=\exp \left[-\frac{r}{2 b}\left(\sigma_{\ln C \mid \Delta t}^{2}+\sigma_{U C \mid \Delta t}^{2}\right)\right], \\
\gamma=\exp \left[\frac{r}{2 b}\left(\sigma_{\ln D \mid h_{\max }, \Delta t}^{2}+\sigma_{U D \mid \Delta t}^{2}\right)\right], \\
\widehat{C}=\alpha-\beta \Delta t, \\
\widehat{D}^{\nu_{0}}=(a+f \Delta t)\left(\frac{\nu_{0}}{k}\right)^{-b / r}, \\
\Omega(0, \Delta t)=\frac{b \alpha}{\beta(b-r)}\left(\frac{a \beta}{-\alpha f+\beta a}\right)^{-r / b} \\
\times[-F(X ; Y ; Z ; x)+F(X ; Y ; Z ; x(\Delta t)) \\
\quad \ldots\left(1+\left(\frac{f \beta \Delta t}{\beta a}\right)^{-r / b}\right)\left(1+\frac{\beta \Delta t}{\alpha}\right) \\
\left.\times\left(\frac{\alpha+\beta \Delta t}{a+f \Delta t}\right)^{-r / b}\left(\frac{\alpha}{a}\right)^{r / b}\right],
\end{gathered}
$$

where $\phi$ and $\gamma$ are the capacity reduction factor and the demand amplification factor at instant $\Delta t$, respectively; $\sigma_{\ln D \mid h_{\max }, \Delta t}^{2}$ and $\sigma_{\ln C \mid \Delta t}^{2}$ are the variances of the natural logarithm of the demand, $D$, given a maximum wave height, $h_{\max }$, and of the structural capacity, $C$, respectively; $\sigma_{U C \mid \Delta t}^{2}$ and $\sigma_{\ln U D \mid \Delta t}^{2}$ represent the epistemic uncertainties associated with the structural demand and the structural capacity respectively; $\widehat{C}$ is the median of the structural capacity at the limit state of interest, which vary linearly in the interval $[0, \Delta t) ; \widehat{D}^{\gamma_{0}}$ is the median of the structural demand caused by environmental loads related to the tolerable annual exceedance rate $v_{0}$, at time $\Delta t ; \Omega(0, \Delta t)$ represents the correction function of the expected number of failures which considers the variation in the interval $[0, \Delta t)$ of the structural demand (given a maximum wave height) and the structural capacity simultaneously.

Hypergeometric functions implicit in (A.6) can be solved using a simpler method by means of the following hypergeometric series [42, 43]:

$$
\begin{aligned}
& F(X, Y ; Z ; x) \\
& =1+\frac{X Y}{1 ! Z} x+\frac{X(X+1) Y(Y+1)}{2 ! Z(Z+1)} x^{2}+\cdots \\
& \quad+\frac{X(X+1) \cdots(X+n-1) Y(Y+1) \cdots(Y+n-1)}{Z(Z+1) \cdots(Z+n-1) n !} X^{n},
\end{aligned}
$$

where

$$
\begin{aligned}
& X=1-\frac{r}{b}, \quad Y=-\frac{r}{b}, \quad Z=2-\frac{r}{b}, \\
& x=\frac{f \alpha}{f \alpha-a \beta}, \quad x(\Delta t)=\frac{f(\beta \Delta t+\alpha)}{f \alpha-a \beta},
\end{aligned}
$$

where $X, Z$, and $x$ represent real numbers, and $Y$ must be an integer. The value $n$ will depend on the problem; for example, for the case analyzed in this study, the hypergeometric series is developed up to $n=5$, in order to obtain a good approximation.

\section{B. Expected Cumulative Total Cost}

The expected cumulative total cost function is defined as the summation of the total expected cost of inspection, repair, and failure at the end of a time interval $[0, \Delta t)$ as follows [25]:

$$
\begin{aligned}
C_{\text {Total }}(0, \Delta t)= & C_{i \mid \Delta t} \cdot e^{-\gamma(\Delta t)-\bar{\eta}_{F}(0, \Delta t)} \\
& +\sum_{j=1}^{n} C_{r_{j} \mid \Delta t} \cdot P\left(D_{j}(\Delta t) \geq d\right) \cdot e^{-\gamma(\Delta t)-\bar{\eta}_{F}(0, \Delta t)} \\
& C_{f \mid \Delta t} \sum_{k=1}^{\widehat{N}} \bar{\eta}_{F}\left(t_{k}-t_{k-1}\right) e^{-\gamma(\Delta t)-\bar{\eta}_{F}\left(0, t_{k}-t_{k-1}\right)},
\end{aligned}
$$

where $C_{i \mid \Delta t}, C_{r_{j} \mid \Delta t}$, and $C_{f \mid \Delta t}$ are the expected cost of inspection, repair, and failure, respectively; $\gamma$ is the discount rate; $\bar{\eta}_{F}$ is the expected number of failures at the end of a time interval considering the variation of the structural capacity and structural demand over time $[0, \Delta t)[24] ; n$ is the number of elements to be repaired; $P\left(D_{j}(\Delta t) \geq d\right)$ is the conditional probability that element $j$ with certain level of cumulative damage $D$, at time $\Delta t$, is higher or equal to an established damage level $d$; $\widehat{N}$ is the number of time intervals of interest; $\bar{\eta}_{F}\left(t_{k}-t_{k-1}\right)$ is the expected number of failures for the time intervals of interest, and $t_{1}, t_{2}, \ldots, t_{N}=1,2, \ldots, \widehat{N}$ years. Equation (B.1) implies that the structure survives up to the end of the time interval of interest.

\section{Acknowledgments}

This research project had the support of DGAPA-UNAM (PAPIIT IN107011-3). The first author thanks CONACYT for the economic support to develop his $\mathrm{PhD}$ research.

\section{References}

[1] J. S. Kong and D. M. Frangopol, "Life-cycle reliability-based maintenance cost optimization of deteriorating structures with emphasis on bridges," Journal of Structural Engineering, vol. 129, no. 6, pp. 818-828, 2003.

[2] A. Miyamoto, K. Kawamura, and H. Nakamura, "Bridge management system and maintenance optimization for existing bridges," Computer-Aided Civil and Infrastructure Engineering, vol. 15, no. 1, pp. 45-55, 2000.

[3] M. Liu and D. M. Frangopol, "Optimal bridge maintenance planning based on probabilistic performance prediction," Engineering Structures, vol. 26, no. 7, pp. 991-1002, 2004.

[4] H. Furuta, T. Kameda, and M. Erami, "A practical bridge management system using new multi-objective genetic algorithm," in Bridge Maintenance, Safety, Management, Life-Cycle Performance and Cost, P. J. S. Cruz, D. M. Frangopol, and L. C. 
Neves, Eds., pp. 131-132, Taylor \& Francis Group, London, UK, 2006.

[5] L. A. C. Neves, D. M. Frangopol, and P. J. S. Cruz, "Probabilistic lifetime-oriented multiobjective optimization of bridge maintenance: single maintenance type," Journal of Structural Engineering, vol. 132, no. 6, pp. 991-1005, 2006.

[6] N. M. Okasha and D. M. Frangopol, "Lifetime-oriented multiobjective optimization of structural maintenance considering system reliability, redundancy and life-cycle cost using GA," Structural Safety, vol. 31, no. 6, pp. 460-474, 2009.

[7] K. Deb, A. Pratap, S. Agarwal, and T. Meyarivan, "A fast and elitist multiobjective genetic algorithm: NSGA-II," IEEE Transactions on Evolutionary Computation, vol. 6, no. 2, pp. 182197, 2002.

[8] R. Skjong, "Reliability based optimization of inspection strategies," in Proceedings of the 4th International Conference on Structural Safety and Reliability (ICOSSAR '85), vol. 3, pp. 614618, Kobe, Japan, 1985.

[9] H. O. Madsen, J. D. Sørensen, and R. Olesen, "Optimal inspection planning for fatigue damage of offshore structures," in Proceedings of the 5th International Conference on Structural Safety and Reliability (ICOSSAR '89), pp. 2099-2106, San Francisco, Calif, USA, August 1989.

[10] J. D. S. Sørensen, M. H. Faber, R. Rackwitz, and P. ThoftChristensen, "Modeling in optimal inspection and repair," in Proceedings of the 10th International Conference on Offshore Mechanics and Arctic Engineering (OMAE '91), pp. 281-288, Stavenger, Noruega, 1991.

[11] P. Thoft-Christensen and J. D. Sørensen, "Optimal strategies for inspection and repair of structural systems," Civil Engineering Systems, vol. 4, no. 2, pp. 94-100, 1987.

[12] T. Moan, O. T. Vardal, N.-C. Hellevig, and K. Skjoldli, "Inservice observations of cracks in North Sea jackets. A study on initial crack depth and POD values," in Proceedings of the 16th International Conference on Offshore Mechanics and Arctic Engineering (OMAE '97), pp. 189-197, Yokohama, Japan, April 1997.

[13] D. Straub, J. D. Sørensen, J. Goyet, and M. H. Faber, "Benefits of risk based inspection planning for offshore structures," in Proceedings of the 25th International Conference on Offshore Mechanics and Arctic Engineering (OMAE '06), pp. 1-10, Hamburg, Germany, June 2006.

[14] M. H. Faber, "Reliability based inspection planning of fatigue damaged offshore platforms," in Proceedings of the 1st International Symposium on Analysis of Structural Risk and Reliability for Offshore Facilities (IMP '01), Cancun, Mexico, 2001.

[15] C. E. O. Estrada and D. de León Escobedo, "Development of a cost-benefit model for inspection of offshore jacket structures in Mexico," in Proceedings of the 22nd International Conference on Offshore Mechanics and Arctic Engineering; Offshore Technology Ocean Space Utilization, pp. 87-98, Cancun, Mexico, June 2003.

[16] J. D. Sørensen and G. Ersdal, "Risk based inspection planning of ageing structures," in Proceedings of the 27th International Conference on Offshore Mechanics and Arctic Engineering (OMAE '08), pp. 399-408, Estoril, Portugal, June 2008.

[17] C. A. Cornell, F. Jalayer, R. O. Hamburger, and D. A. Foutch, "Probabilistic basis for 2000 SAC federal emergency management agency steel moment frame guidelines," Journal of Structural Engineering, vol. 128, no. 4, pp. 526-533, 2002.

[18] C. A. Cornell, "Calculating building seismic performance reliability: a basis for multi-level design norms," in Proceedings of the 11th World Conference on Earthquake Engineering, 1996, paper no. 2122.

[19] Federal Emergency Management Agency (FEMA), "Recommended seismic evaluation and upgrade criteria for existing welded steel moment-frame buildings," Tech. Rep. FEMA 351, SAC Joint Venture, Washington, DC, USA, 2000.

[20] S.-Y. Yun, R. O. Hamburger, C. A. Cornell, and D. A. Foutch, "Seismic performance evaluation for steel moment frames," Journal of Structural Engineering, vol. 128, no. 4, pp. 534-545, 2002.

[21] M. A. Torres and S. E. Ruiz, "Structural reliability evaluation considering capacity degradation over time," Engineering Structures, vol. 29, no. 9, pp. 2183-2192, 2007.

[22] D. Celarec, D. Vamvatsikos, and M. Dolšek, "Simplified estimation of seismic risk for reinforced concrete buildings with consideration of corrosion over time," Bulletin of Earthquake Engineering, vol. 9, no. 4, pp. 1137-1155, 2011.

[23] D. Vamvatsikos and M. Dolšek, "Equivalent constant rates for performance-based seismic assessment of ageing structures," Structural Safety, vol. 33, no. 1, pp. 8-18, 2011.

[24] D. Tolentino, S. E. Ruiz, and M. A. Torres, "Simplified closedform expressions for the mean failure rate of structures considering structural deterioration," Structure and Infrastructure Engineering, vol. 8, no. 5, pp. 483-496, 2012.

[25] D. Tolentino, Optimización multiobjetivo para el mantenimiento de estructuras considerando la influencia del daño acumulado [Ph.D. thesis], Graduate Program in Engineering, Universidad Nacional Autónoma de México, 2013 (Spanish).

[26] D. E. Goldberg, Genetic Algorithms in Search, Optimization and Machine Learning, Addison Wesley Longman Inc., Boston, Mass, USA, 1989.

[27] M. Fragiadakis, N. D. Lagaros, and M. Papadrakakis, "Performance-based multiobjective optimum design of steel structures considering life-cycle cost," Structural and Multidisciplinary Optimization, vol. 32, no. 1, pp. 1-11, 2006.

[28] O. Lavan and G. F. Dargush, "Multi-objective evolutionary seismic design with passive energy dissipation systems," Journal of Earthquake Engineering, vol. 13, no. 6, pp. 758-790, 2009.

[29] K. Deb, Multi-Objective Optimization Using Evolutionary Algorithms, John Wiley \& Sons, Chichester, UK, 2001.

[30] D. E. Goldberg and K. Deb, "A comparative analysis of selection schemes used in genetic algorithms," in Foundations of Genetic Algorithms (Bloomington, IN, 1990), G. J. E. Rawlins, Ed., pp. 69-93, Morgan Kaufmann, San Mateo, Calif, USA, 1991.

[31] H. M. Mühlenbein and D. Schlierkamp-Voosen, "Predictive models for the breeder genetic algorithm," Evolutionary Computation, vol. 1, no. 1, pp. 25-49, 1993.

[32] The MathWorks, Global Optimization Toolbox 3 User's Guide, Version 3.1, 2010.

[33] F. L. Silva and E. Heredia, "Effect of uncertainties on the reliability of fatigue damaged systems," in Proceedings of the 23th International Conference on Offshore Mechanics and Arctic Engineering (OMAE '04), vol. 2, pp. 427-434, Vancouver, Canada, 2004.

[34] P. Paris and F. A. Erdogan, "Critical analysis of crack propagation laws," Journal of Basic Engineering, vol. 85, pp. 258-534, 1963.

[35] K. Sobczyk and F. B. Spencer, Random Fatigue: From Data Theory, Academic Press, Boston, Mass, USA, 1992.

[36] A. Stacey, J. V. Sharp, and N. W. Nichols, "Static strength assessment of cracked tubular joints," in Proceedings of the 
15th International Conference on Offshore Mechanics and Arctic Engineering (OMAE '96), vol. 3, pp. 211-224, June 1996.

[37] F. M. Burdekin, "The static strength of cracked joints in tubular members," Offshore Technology Report 2001/080, Health and Safety Executive, London, UK, 2002.

[38] American Petroleum Institute (API), Recommended Practice for Planning Designing and Construction of Fixed Offshore Platforms Load and Resistance Factor Design, API RP 2a-LRFD, Washington, DC, USA, 1993.

[39] PEMEX, "Design and evaluation of fixed marine platforms in Campeche Bay," NRF-2003-Pemex-2000, Mexico, 2000.

[40] A. Raine, "The development of Alternating Current Field Measurement (ACFM) technology as a technique for the detection of surface breaking defects in conducting material and its use in commercial and industrial applications," in Proceedings of the 15th World Conference on Non-Destructive Testing, Rome, Italy, 2000.

[41] The Marine Technology Directorate Limited, Review of Repairs to Offshore Structures and Pipelines, vol. 94-102, 1994.

[42] L. R. Ford, Differential Equations, McGraw-Hill Book Company, New York, NY, USA, 1955.

[43] E. D. Rainville, Intermediate Course in Differential Equations, John Wiley \& Sons, New York, NY, USA, 1961. 


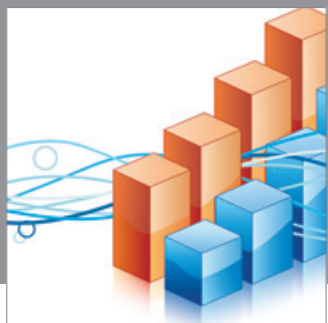

Advances in

Operations Research

mansans

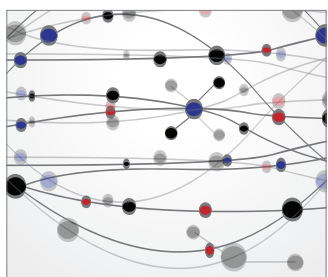

The Scientific World Journal
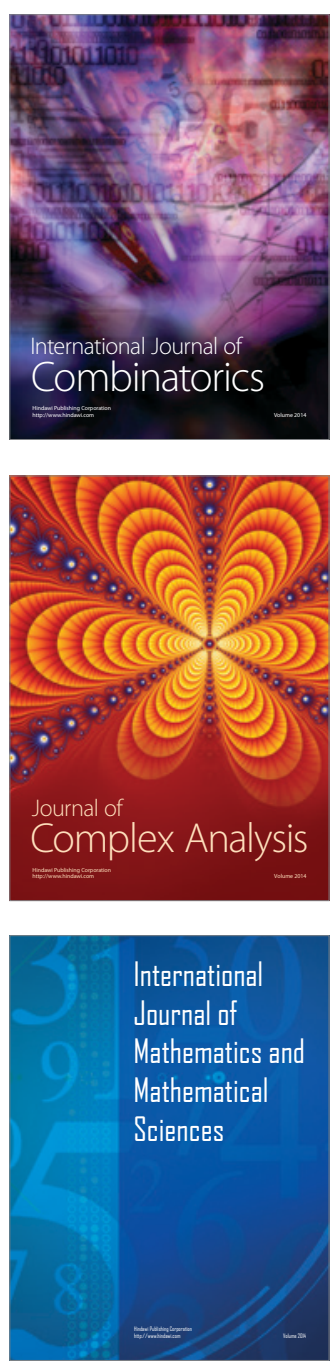
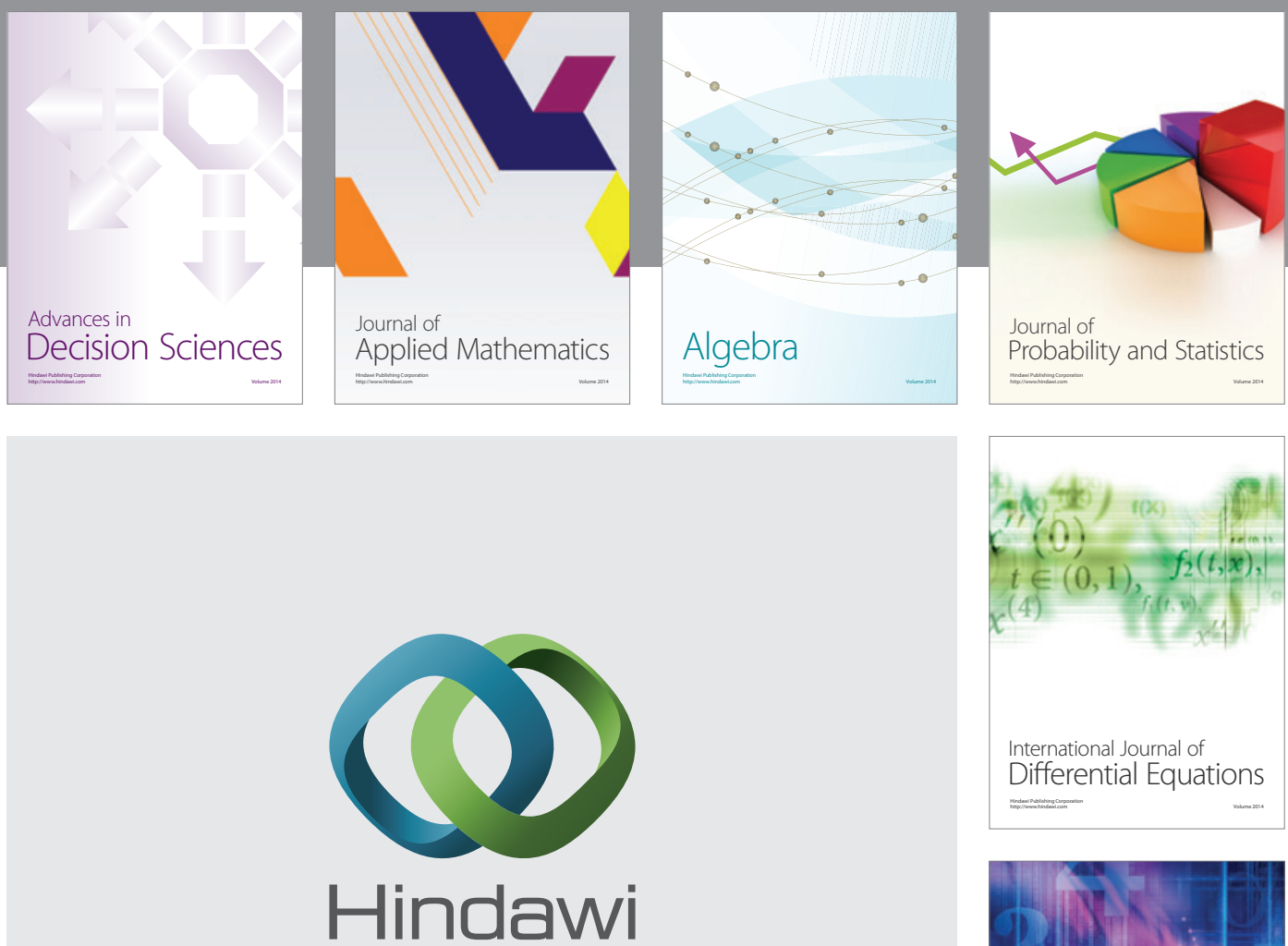

Submit your manuscripts at http://www.hindawi.com
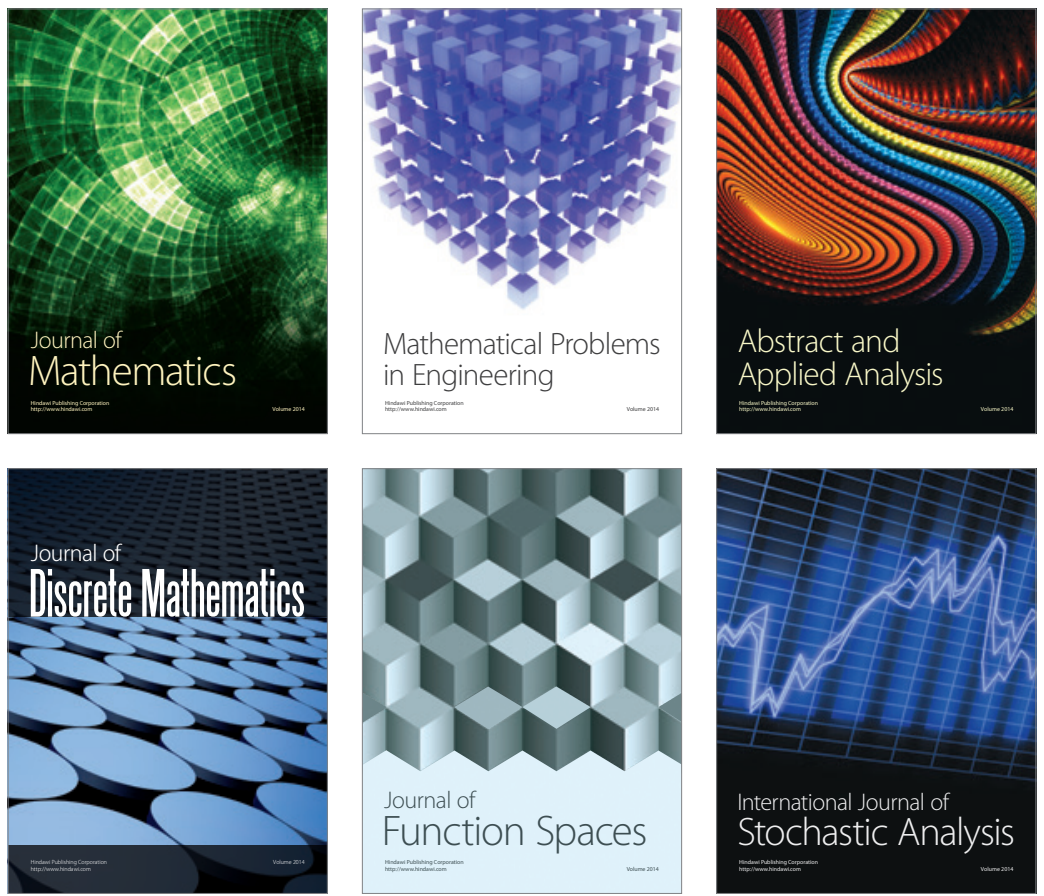

Journal of

Function Spaces

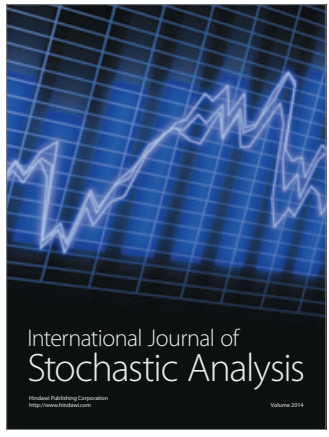

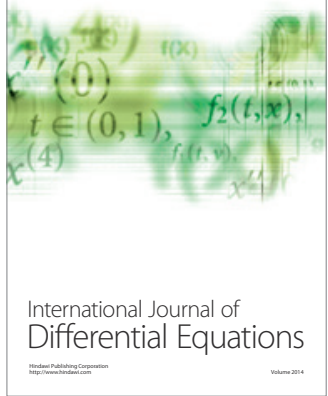
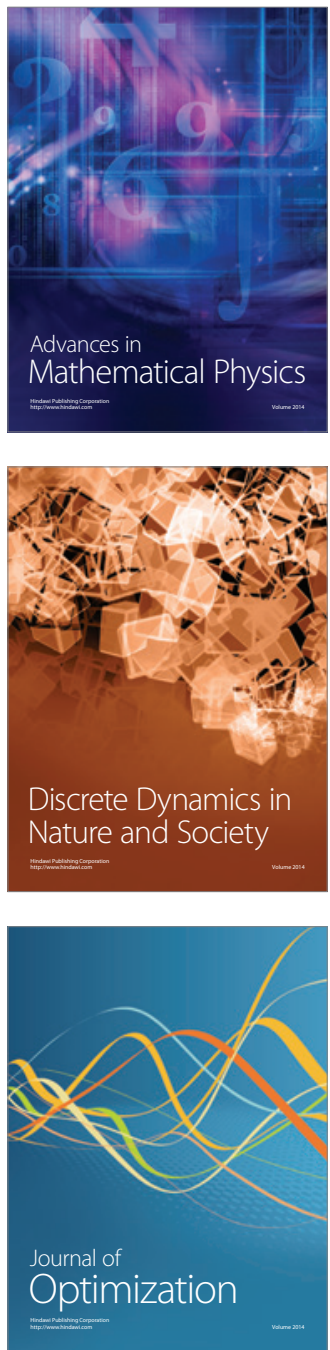